\title{
Bronchial inflammation in chronic bronchitis assessed by measurement of cell products in bronchial lavage fluid
}

Gerdt C Riise, Staffan Ahlstedt, Sven Larsson, Ingrid Enander, Ilona Jones, Peter Larsson, Bengt Andersson

\begin{abstract}
Background - Bronchial inflammation in chronic bronchitis has not been characterised as well as in asthma. The present study was undertaken to assess whether a characteristic pattern of bronchial inflammatory markers could be found in patients with chronic bronchitis.

Methods - Bronchoscopy with bronchial lavage was performed in 42 patients with chronic bronchitis and in 13 healthy controls. Twenty three of the patients had non-obstructive chronic bronchitis and 19 had chronic bronchitis and chronic obstructive pulmonary disease (COPD). Eighteen of the patients with bronchitis had recurrent infective exacerbations and 24 did not. Intrabronchial bacterial cultures were taken with a protected specimen brush.

Results - Increased activity of neutrophils, fibroblasts, and eosinophils was found in the patients with chronic bronchitis as assessed by the levels of myeloperoxidase (MPO) and interleukin-8 (IL-8), hyaluronan, and eosinophil cationic protein (ECP), respectively. The levels of tryptase did not differ from the controls. High correlations were found between the levels of MPO and IL-8, as well as ECP and IL-8. No differences were found between the patients with COPD and those with nonobstructive chronic bronchitis.

Conclusions - Recruitment and activation of both neutrophils and eosinophils seem to be a characteristic of chronic bronchitis. This activation is associated with $\mathrm{IL-8}$. The patients with intrabronchial cultures of Streptococcus pneumoniae had the highest individual levels of MPO, ECP, and IL-8 of all subjects in the study, indicating that colonisation with $S$ pneumoniae could promote bronchial inflammation.

(Thorax 1995;50:360-365)
\end{abstract}

Keywords: chronic bronchitis, chronic obstructive pulmonary disease, airways inflammation, eosinophils, neutrophils.

Chronic bronchitis is a clinical entity characterised by cough and mucus hypersecretion. It can be associated with bronchial obstruction (chronic obstructive pulmonary disease, COPD) and recurring infective exacerbations. ${ }^{1}$ The pathological changes in the respiratory tract consist of goblet cell hyperplasia and submucosal gland hypertrophy, as well as bronchial inflammation. ${ }^{23}$
The airways inflammation in chronic bronchitis has not been characterised as well as in $\approx$ bronchial asthma. Histopathological studies of $\vec{\circ}$ large airways mucosa in patients with chronic bronchitis have demonstrated infiltration of mononuclear phagocytes, ${ }^{4}$ lymphocyte infiltration, and lymphocyte activation. ${ }^{5}$ In contrast, mucosal changes in asthmatic patients have shown a predominance of eosinophils and mast cells. ${ }^{6-9}$

Bronchoalveolar lavage (BAL) fluid, as well as bronchial lavage fluid, from patients with chronic bronchitis has shown raised levels of macrophages and neutrophil granulocytes. ${ }^{1011}$ In lavage fluid from patients with chronic bronchitis one would therefore expect to find products from activated neutrophil granulocytes such as myeloperoxidase (MPO), and chemotactic factors for neutrophil granulocytes such as interleukin 8 (IL-8). In addition, since high levels of the acute phase reactant interleukin 6 (IL-6) have been found in the urine of patients with asymptomatic bacteriuria, ${ }^{12}$ this could also be a potential marker of local bacterial colonisation and bronchial mucosal inflammation in lavage fluid from patients with chronic bronchitis.

We wished to study whether the airways inflammation in smokers with chronic bronchitis is reflected in raised levels of inflammatory markers in bronchial lavage fluid compared with healthy non-smoking controls. The second aim was to determine whether levels of in- 을 flammatory markers differed between patients $\rightarrow$ with non-obstructive chronic bronchitis and patients with chronic bronchitis and COPD, as N well as between patients with chronic bronchitis and recurrent infective exacerbations and those without. The third objective was to assess whether the levels of markers correlated with the intrabronchial bacterial flora in the patient groups.

Methods

STUDY DESIGN

Small volume lavage of the large airways was used, a method known to give samples predominantly representative of the bronchial epi- \& thelium. ${ }^{13-15}$ The presence of MPO, tryptase, hyaluronan, and eosinophil cationic protein (ECP) were used as indirect markers for ac- $\stackrel{?}{\rightleftharpoons}$ tivation of neutrophils, mast cells, fibroblasts and eosinophils, respectively, and IL-6 and IL8 were used to indicate a broader activation of cells including epithelial cells, granulocytes, and lymphocytes. All patients were investigated during an infection-free period. 
Table 1 Mean (range) age, sex, and mean (SE), FEV (\% of predicted normal) and cigarette consumption (pack years) of healthy non-smoking controls and patients with chronic bronchitis

\begin{tabular}{|c|c|c|c|c|c|}
\hline \multicolumn{2}{|l|}{ Subjects } & $n$ & Age (years) & $F E V_{1}$ & Pack years \\
\hline \multicolumn{2}{|c|}{$\begin{array}{l}\text { A. Healthy controls }(4 \mathrm{M} / 9 \mathrm{~F}) \\
\text { B. Chronic bronchitis }(22 \mathrm{M} / 20 \mathrm{~F})\end{array}$} & $\begin{array}{l}13 \\
42\end{array}$ & $\begin{array}{l}47(26-66) \\
55(36-70)\end{array}$ & $101(1)$ & 0 \\
\hline$B(1 a)$ & $\begin{array}{l}\text { Non-obstructive chronic } \\
\text { bronchitis }(10 \mathrm{M} / 13 \mathrm{~F})\end{array}$ & 23 & $52(36-38)$ & $93(2)$ & $37(2)$ \\
\hline$B(1 b)$ & $\begin{array}{l}\text { Chronic bronchitis with } \\
\text { COPD }(12 \mathrm{M} / 7 \mathrm{~F})\end{array}$ & 19 & $57(38-70)$ & $63(2)^{* *}$ & $44(4)$ \\
\hline $\mathrm{B}(2 \mathrm{a})$ & $\begin{array}{l}\text { Chronic bronchitis without } \\
\text { infective exacerbations }(16 \mathrm{M} / 8 \mathrm{~F})\end{array}$ & 24 & $55(36-70)$ & $81(4)^{* *}$ & $40(3)$ \\
\hline$B(2 b)$ & $\begin{array}{l}\text { Chronic bronchitis with } \\
\text { infective exacerbations }(6 \mathrm{M} / 12 \mathrm{~F})\end{array}$ & 18 & $54(38-68)$ & $77(4)^{* *}$ & $40(4)$ \\
\hline
\end{tabular}

${ }^{* *} \mathrm{p}<0.01,{ }^{* * *} \mathrm{p}<0.001 v$ controls (Mann-Whitney U test with Bonferroni's correction for multiple comparisons).

\section{SUBJECTS}

Thirteen healthy lifelong non-smoking volunteers with normal spirometric values and no signs of infective respiratory disease during the past four weeks comprised a control group (group A). They were compared with 42 patients with chronic bronchitis (group B), all of whom were current smokers with a productive daily cough for at least three consecutive months each year for the past two years. These patients were subdivided into two groups according to the presence or absence of airways obstruction: group B (1a) -23 patients with non-obstructive chronic bronchitis and normal spirometric values, and group B (1b) 19 patients with chronic bronchitis and COPD (defined as a forced expiratory volume in one second $\left(\mathrm{FEV}_{1}\right)$ of less than $80 \%$ of predicted and a reversibility less than $10 \%$ on $\beta_{2}$ agonists). They could also be subdivided into two groups according to the presence or absence of infective exacerbations: group B (2a) - 24 patients without a history of recurrent infective exacerbations, and group $B(2 b)-18$ patients with three or more antibiotic treated infective exacerbations during the past two years as defined by Boman et al. ${ }^{16}$

The patients with chronic bronchitis were slightly older and had a lower mean maximum $\mathrm{FEV}_{1}$ (percentage predicted normal) than the healthy controls. The smoking history (in pack years) and age between subgroups of patients with chronic bronchitis were comparable (table 1).

Of the 23 patients with non-obstructive chronic bronchitis, none used oral $\mathrm{N}$-acetylcysteine or inhaled medication on a regular basis. Of the 19 patients with chronic bronchitis and COPD, eight used oral $\mathrm{N}$-acetylcysteine regularly (200 mg at least twice daily) and four used inhaled corticosteroids regularly. No patients used theophylline preparations or oral steroids.

The duration of symptoms in the patient group varied from 2.5 years to 24 years with a mean of 12.5 years. Criteria for exclusion were abnormal chest radiography, bronchial hypersecretion caused by factors other than cigarette smoking, a history of asthma or reversibility $>10 \%$ after $\beta_{2}$ agonists, and for safety reasons an $\mathrm{FEV}_{1}$ less than $50 \%$ predicted or age more than 70 years. Ventilatory function $\left(\mathrm{FEV}_{1}\right)$ was measured with a Bernstein spirometer or Vitalograph.

The study design was approved by the ethical committee of the University of Göteborg and the volunteers gave their consent after both written and oral information.

\section{FIBREOPTIC BRONCHOSCOPY}

Premedication was given with haloperidol $5 \mathrm{mg}$ orally followed by $0 \cdot 5-1 \mathrm{ml}$ morphine-scopolamine intramuscularly. Five $\mathrm{ml} 1 \%$ tetracaine without preservative was nebulised (Plug-in inhalator, Aiolos Systems, Karlstad, Sweden) and inhaled in an upright position for local anaesthesia. All bronchoscopies were performed transorally by one of two experienced bronchoscopists, and with the patients in the supine position. Several models of Olympus flexible fiberoptic bronchoscopes were used.

Bacterial samples were taken during bronchoscopy according to the method of Wimberley et al using a telescoping double catheter protected specimen brush (Microvasive catheter no. 1650). ${ }^{17}$ All bacterial samples were taken during an infection free period and the detailed results have been published. ${ }^{18}$

\section{COLLECTION OF SAMPLES}

All samples were collected between 08.30 and 10.00 hours. Bronchial lavage fluid was collected by a single instillation of $5 \mathrm{ml}$ sterile phosphate buffered saline (PBS) with the bronchoscope in an unwedged position in the anterior segment of the right upper lobe. The fluid was immediately aspirated, collected in a sterile container, and transported to the laboratory where it was frozen at $-20^{\circ} \mathrm{C}$. Before analysis the fluid was thawed and centrifuged at $10000 \mathrm{~g}$ for 15 minutes. The supernatant was used for analysis as published previously. ${ }^{19}$

\section{ANALYSIS OF INFLAMMATORY MARKERS}

Kits for analysis of ECP, ${ }^{20} \mathrm{MPO},{ }^{21}$ tryptase, ${ }^{22}$ and hyaluronan ${ }^{23}$ (Pharmacia Diagnostics $A B$, Uppsala, Sweden) were used according to the instructions of the manufacturers. To ascertain the validity of the assay an analysis of recovery of ECP was performed on three samples and the measured values were within $20 \%$ of the expected value (data not shown).

IL-6 was determined with the B9 bioassay previously described. ${ }^{122}$ Briefly, the B9 cells were added at 5000 cells per well into microtitre plates (Nunc, Roskilde, Denmark) containing dilutions of sample or a standard preparation consisting of recombinant human IL-6. The medium used was Iscoves Modified Dulbeccos Medium (Flow Laboratories, Irvine, UK) supplemented with $50 \mu \mathrm{M} 2$-mercaptoethanol, $5 \%$ fetal calf serum, and gentamicin $(0.1 \mathrm{mg} / \mathrm{ml})$ in a total volume of $0.2 \mathrm{ml}$. After $68-72$ hours of culture ${ }^{3} \mathrm{H}$-thymidine was added, the incorporated radioactivity was measured and compared with a standard curve. The standard curve was prepared using stock recombinant human IL-6 (8000 units $/ \mathrm{ml}$; 1 unit $=$ concentration of IL-6 required for a half maximal thymidine incorporation). The activities of each sample are given as units/ml compared with the standard curve. 
IL-8 was analysed using a solid phase double ligand ELISA prototype method. Briefly, the bronchial lavage fluid was incubated in microtitre wells coated with a mouse monoclonal antibody against IL-8. All samples were diluted in the standard dilution buffer. After washing a goat anti-IL-8 horseradish peroxidase conjugate was added and the plates were incubated. The amount of IL-8 was measured spectrophotometrically after adding tetramethylbenzidine as enzyme substrate. Recombinant IL $-8^{25}$ was used as standard, ranging from $25 \mathrm{ng} / \mathrm{l}$ to $1600 \mathrm{ng} / \mathrm{l}$. The intra-assay and interassay coefficients of variation were less then $10 \%$ and the detection limit was $10 \mathrm{ng} / \mathrm{l}$.

\section{DATA ANALYSIS}

Results are expressed as arithmetic mean, median, and standard deviations (SD). The Kruskal-Wallis test was used to analyse the significance of differences in data between the controls, the patients with non-obstructive chronic bronchitis, and the patients with chronic bronchitis and COPD. The MannWhitney $U$ test was used for the comparison of the distribution of the inflammatory markers between subgroups of subjects, and Spearman's rank correlation test for possible associations between markers. Multiple regression was per- formed to analyse the possible interdependence of clinical factors and inflammatory markers. Bonferroni's correction for the risk of mass significance with multiple comparisons between the four subgroups $(B(1 a), B(1 b), B(2 a)$, and $B(2 b)$ ) was performed.

\section{Results}

INFLAMMATORY MARKERS IN CONTROLS AND PATIENTS WITH CHRONIC BRONCHITIS

The patients with chronic bronchitis (group B) had significantly higher mean levels of MPO ( $p<0.01)$, IL-8 ( $<<0.01)$, hyaluronan $(p<0.001)$, and ECP $(p<0.001)$ than the controls (figs 1 and 2). The mean levels of tryptase, IL-6, and albumin did not differ statistically between the patients with chronic bronchitis and the controls.

When albumin values were used as a denominator for each marker the differences in levels of markers between the groups were still present, but the statistical significances were lost (data not shown).

INFLAMMATORY MARKERS IN PATIENTS WITH AND WITHOUT AIRWAYS OBSTRUCTION

The patients with chronic bronchitis and COPD (subgroup B(1b)) did not differ in levels
Figure 1 Levels of $(A)$ myeloperoxidase (MPO) $(\mu g / l)$ and $(B) I L-8(\mu g / l)$ in bronchial lavage fluid in normal controls $(n=13)$ and in patients with

chronic bronchitis $(n=42)$

Bold lines represent mean values, dotted lines represent median values. Data are presented on a logarithmic scale. ${ }_{* *}^{* *}<0 \cdot 01$.
Figure 2 Levels of $(A)$ hyalumnan $(H A)(\mu g / l)$ and $(B)$ eosinophil cationic protein (ECP) ( $\mu \mathrm{g} / \mathrm{l})$ in bronchial lavage fluid in normal controls $(n=13)$ and in patients with chronic bronchitis $(n=42)$. Bold lines represent mean values, dotted lines represent median values. Data are presented on a logarithmic scale. $* * * p<0.001$
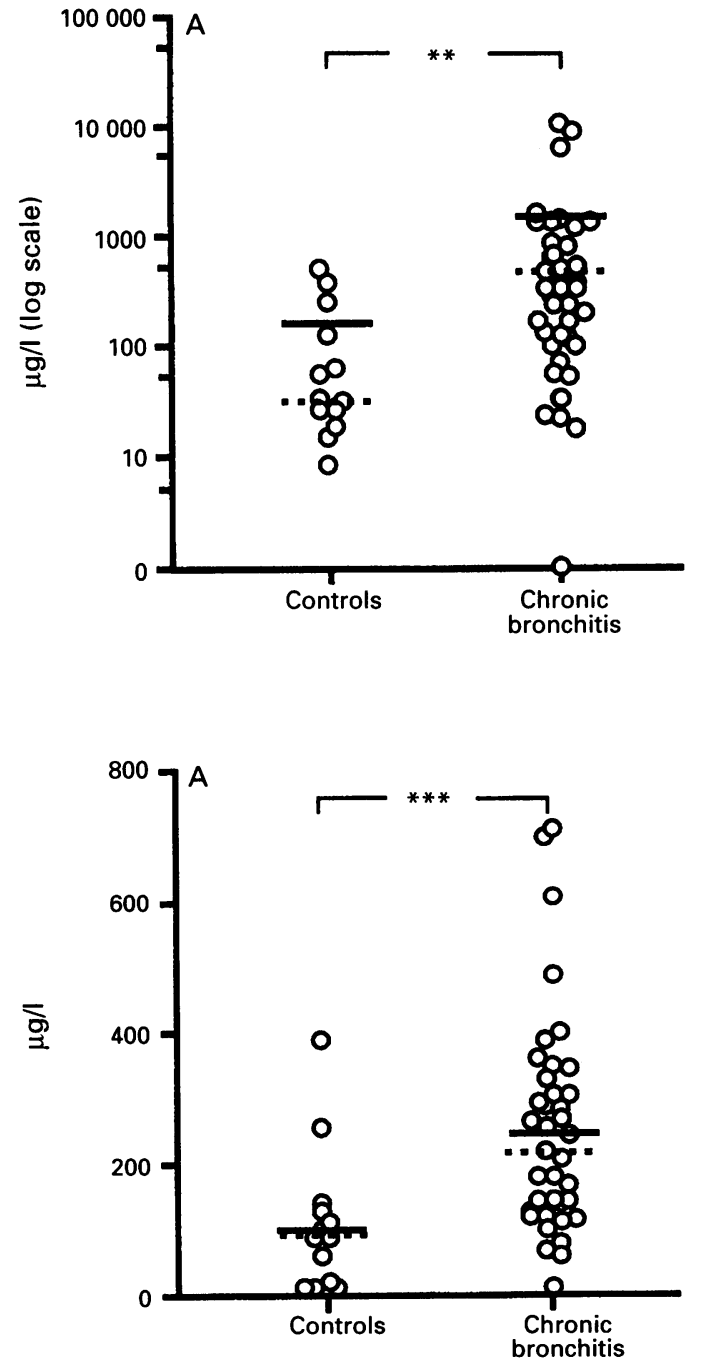
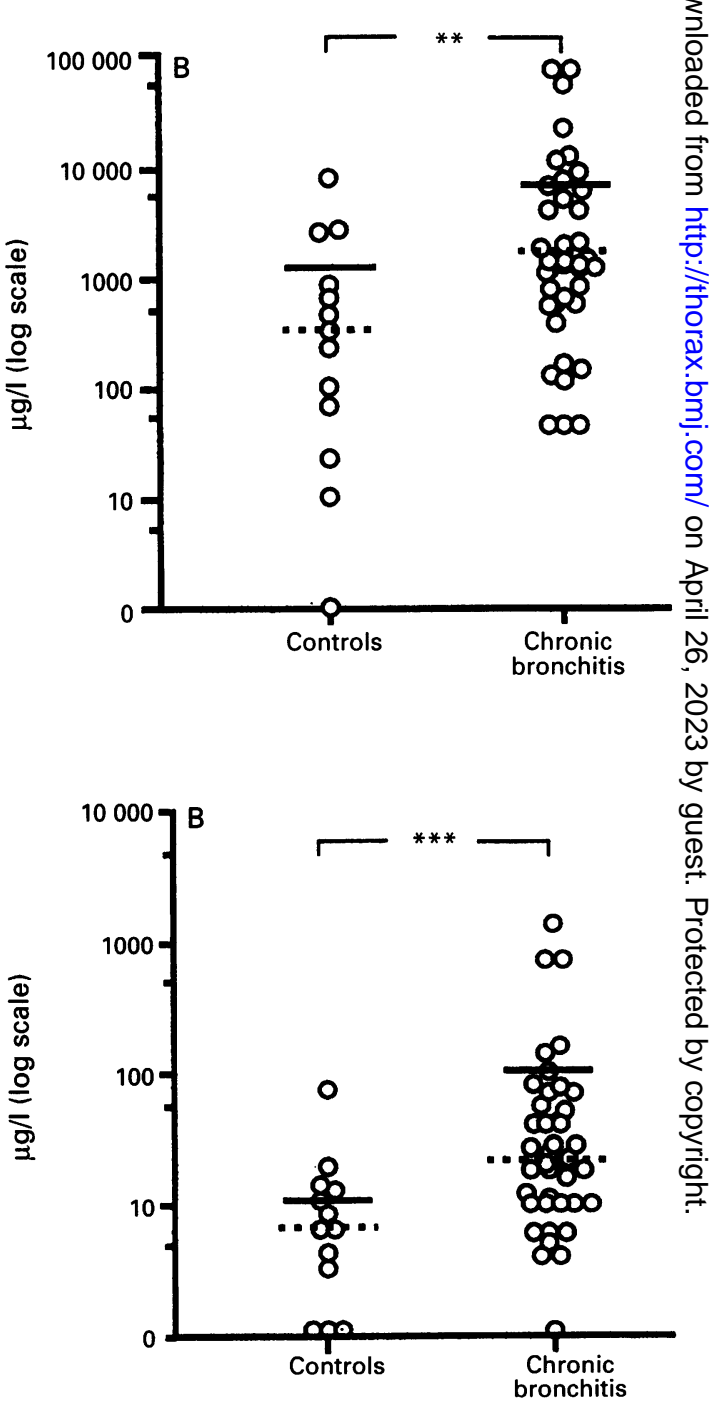
Table 2 Mean (median) levels of inflammatory markers in the controls compared with levels in the four subgroups of patients with chronic bronchitis

\begin{tabular}{|c|c|c|c|c|c|c|c|}
\hline \multicolumn{2}{|c|}{ Subjects } & \multirow{2}{*}{$\begin{array}{c}\begin{array}{c}M P O \\
(\mu g / l)\end{array} \\
\begin{array}{c}125 \\
(36)\end{array}\end{array}$} & \multirow{2}{*}{$\begin{array}{c}\begin{array}{l}I L-8 \\
(\mu g / l)\end{array} \\
1216 \\
(360)\end{array}$} & \multirow{2}{*}{$\begin{array}{c}\begin{array}{l}H A \\
(\mu g / l)\end{array} \\
107 \\
(92)\end{array}$} & \multirow{2}{*}{$\begin{array}{c}\begin{array}{c}E C P \\
(\mu g / l)\end{array} \\
12 \\
(6)\end{array}$} & \multirow{2}{*}{$\begin{array}{l}\text { Tryptase } \\
\text { (units/l) }\end{array}$} & \multirow{2}{*}{$\begin{array}{c}\begin{array}{c}\text { Albumin } \\
(\mu g / l)\end{array} \\
\begin{array}{c}50 \\
(38)\end{array}\end{array}$} \\
\hline A $\mathrm{H}$ & Healthy controls & & & & & & \\
\hline $\begin{array}{l}B(1 a) \\
B(1 b)\end{array}$ & $\begin{array}{l}\text { Non-obstructive } \\
\text { chronic bronchitis } \\
\text { Chronic bronchitis } \\
\text { with COPD }\end{array}$ & $\begin{array}{l}1028 \\
(280) \\
1263^{* *} \\
(400)\end{array}$ & $\begin{array}{l}5649 \\
(1108) \\
10733 \\
(1088)\end{array}$ & $\begin{array}{l}208 \\
(144) \\
295^{* *} \\
(260)\end{array}$ & $\begin{array}{l}60 \\
(20) \\
146^{* *} \\
(26)\end{array}$ & $\begin{array}{l}6 \cdot 7 \\
(4) \\
7 \cdot 5 \\
(4)\end{array}$ & $\begin{array}{c}96 \\
(76) \\
90 \\
(72)\end{array}$ \\
\hline $\begin{array}{l}B(2 a) \\
B(2 b)\end{array}$ & $\begin{array}{l}\text { Chronic bronchitis } \\
\text { without exacerbations } \\
\text { Chronic bronchitis } \\
\text { with exacerbations }\end{array}$ & $\begin{array}{l}801^{* *} \\
(400) \\
1506 \\
(220)\end{array}$ & $\begin{array}{l}6465 \\
(1120) \\
9877 \\
(1086)\end{array}$ & $\begin{array}{l}190^{*} \\
(157) \\
318^{* *} \\
(288)\end{array}$ & $\begin{array}{l}99^{* *} \\
(24) \\
100^{* *} \\
(21)\end{array}$ & $\begin{array}{l}5 \cdot 0 \\
(3) \\
9 \cdot 7 \\
(4)\end{array}$ & $\begin{array}{c}76 \\
(65) \\
117 \\
(120)\end{array}$ \\
\hline
\end{tabular}

$\mathrm{MPO}=$ myeloperoxidase; IL-8 = interleukin-8; $\mathrm{HA}=$ hyaluronan; $\mathrm{ECP}=$ eosinophil cationic protein.

${ }^{*} \mathrm{p}<0.05,{ }^{* *} \mathrm{p}<0.01 v$ controls (Mann-Whitney U test with Bonferroni's correction for multiple comparisons).

of MPO, IL-8, hyaluronan, or ECP compared with the non-obstructive patients (subgroup $\mathrm{B}(1 \mathrm{a})$ ), even though their mean values were higher (table 2). The mean levels of tryptase, IL-6, and albumin were also comparable between the groups.

For the patients with chronic bronchitis and COPD (subgroup $B(1 b)$ ) the mean levels of MPO, hyaluronan, and ECP were significantly higher than the controls (table 2). The mean level of IL-8 was raised in the patients with chronic bronchitis and COPD, but not significantly so when Bonferroni's correction had been applied. The mean level of tryptase, IL-6, and albumin were comparable between each subgroup of patients with chronic bronchitis and the controls.

INFLAMMATORY MARKERS IN PATIENTS WITH AND WITHOUT INFECTIVE EXACERBATIONS Patients with chronic bronchitis and recurrent exacerbations (subgroup $B(2 b)$ ) had a higher mean level of hyaluronan than those without a history of recurrent infections (subgroup $B(2 a)$ ), but the difference was not statistically significant when Bonferroni's correction had been applied (table 2). No differences were seen in levels of MPO, IL-8, or ECP between bronchitis patients with and without exacerbations, and the mean levels of tryptase, IL-6, and albumin were comparable between the two groups (table 2).

ANALYSIS OF LEVELS OF MARKERS IN RELATION TO INTRABRONCHIAL BACTERIAL GROWTH Ten patients with chronic bronchitis had significant bacterial growth when the established cutoff level of $>10^{3}$ colony forming units per $\mathrm{ml}$ for the protected specimen brush was used. ${ }^{1718}$ Their mean levels of MPO, IL-8, hyaluronan, and ECP were higher than for the other 32 patients who had low bacterial numbers, but not significantly (data not shown).

Two of the three patients with intrabronchial cultures of Streptococcus pneumoniae were found to have the highest individual levels of MPO, IL-8, and ECP of all subjects in the study (table 3 ). The levels of markers in the two patients with cultures of Haemophilus influenzae, and in those with significant growth of other bacterial strains, were similar to the levels in the patients without significant intrabronchial bacterial growth (table 3).

The significant differences in mean levels of MPO, IL-8, hyaluronan, and ECP between the patients with chronic bronchitis and COPD compared with the controls were still valid when the high values for the patients with intrabronchial cultures of Streptococcus pneumoniae had been subtracted.

\section{CORRELATIONS BETWEEN PARAMETERS}

Highly significant correlations were found between the ECP and MPO levels (rho=0.74; $\mathrm{p}<0.001$, Spearman's rank test) and the ECP and IL-8 levels (rho $=0.75 ; \mathrm{p}<0.001$, Spearman's rank test). The correlation between MPO and IL-8 levels was also highly significant (rho $=0.87 ; \mathrm{p}<0.001$, Spearman's rank test) (fig 3). The levels of tryptase, hyaluronan, and albumin showed no correlation with any of the other markers.

None of the clinical paramaeters - age, smoking habits, airway medication including $N$-acetylcysteine, duration of bronchitis symptoms,

Figure 3 Levels of inflammatory markers in the five patients with intrabronchial bacterial growth of Streptococcus pneumoniae and Haemophilus influenzae. Median levels are given for patients with chronic bronchitis with and without bacterial growth for comparison

\begin{tabular}{|c|c|c|c|c|c|c|c|}
\hline \multicolumn{2}{|l|}{ Bacteria (cfu/ml) } & \multirow{2}{*}{$\begin{array}{r}\begin{array}{r}M P O \\
(\mu g / l)\end{array} \\
320 \\
7360 \\
10880\end{array}$} & \multirow{2}{*}{$\begin{array}{r}\begin{array}{l}I L-8 \\
(\mu g / l)\end{array} \\
4400 \\
80000 \\
80000\end{array}$} & \multirow{2}{*}{$\begin{array}{l}\begin{array}{l}H A \\
(\mu g / l)\end{array} \\
\frac{120}{704}\end{array}$} & \multirow{2}{*}{$\begin{array}{r}E C P \\
(\mu g / l)\end{array}$} & \multirow{2}{*}{$\begin{array}{l}\begin{array}{l}\text { Tryptase } \\
\text { (units/l) }\end{array} \\
9 \\
2 \\
2\end{array}$} & \multirow{2}{*}{$\begin{array}{c}\begin{array}{c}\text { Albumin } \\
(\mu g / l)\end{array} \\
80 \\
148 \\
152\end{array}$} \\
\hline $\begin{array}{l}S \text { pneumoniae } \\
S \text { pneumoniae } \\
S \text { pneumoniae }\end{array}$ & $\begin{array}{l}\left(5 \times 10^{1}\right) \\
\left(2 \times 10^{2}\right) \\
\left(5 \times 10^{4}\right)\end{array}$ & & & & & & \\
\hline $\begin{array}{l}H \text { influenzae } \\
H \text { influenzae }\end{array}$ & $\begin{array}{l}\left(3 \times 10^{2}\right) \\
\left(3 \times 10^{4}\right)\end{array}$ & $\begin{array}{l}124 \\
200\end{array}$ & $\begin{array}{r}40 \\
1132\end{array}$ & $\begin{array}{r}60 \\
360\end{array}$ & $\begin{array}{r}6 \\
10\end{array}$ & $\begin{array}{l}3 \\
3\end{array}$ & $\begin{array}{l}10 \\
38\end{array}$ \\
\hline \multirow{2}{*}{\multicolumn{2}{|c|}{$\begin{array}{l}\text { Other strains } \\
\text { (median levels) } \\
\text { Non-significant } \\
\text { growth (median levels) }\end{array}$}} & 240 & 872 & 284 & 10 & 4 & 36 \\
\hline & & 280 & 1042 & 176 & 21 & 4 & 71 \\
\hline
\end{tabular}

$\mathrm{MPO}=$ myeloperoxidase; IL-8 = interleukin-8; $\mathrm{HA}=$ hyaluronan, $\mathrm{ECP}=$ eosinophil cationic protein; cfu/ml = colony forming units per $\mathrm{ml}$. 
Figure 3 Association between levels of IL-8 $(\mu g / l)$ and myeloperoxidase (MPO) ( $\mu g / l)$ using Spearman's rank correlation test. $A$ strong positive correlation was found. Data are presented on a logarithmic scale.

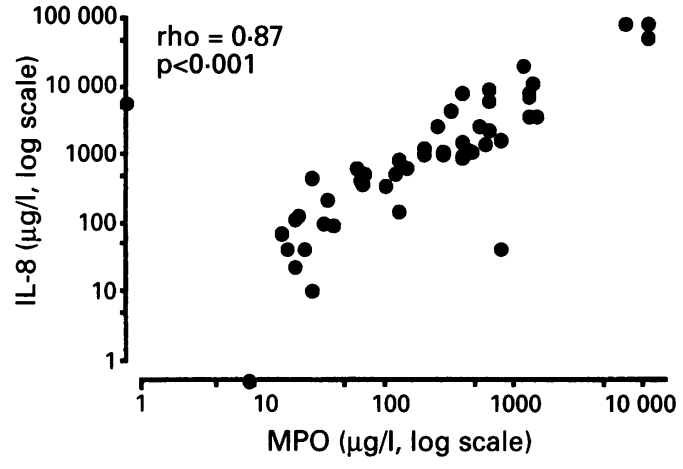

or lung function $\left(\mathrm{FEV}_{1}\right.$ percentage predicted normal) - had any correlations with the markers studied.

\section{Discussion}

In this study significantly higher activity of neutrophils, fibroblasts, and eosinophils as assessed by levels of MPO, IL-8, hyaluronan, and ECP, respectively, were found in bronchial lavage fluid samples from smokers with chronic bronchitis than from healthy non-smoking controls. However, the levels of tryptase - a mediator known to be related to the activation of mast cells and found in high levels in asthmatics ${ }^{26}$ - were similar between the two groups.

Earlier findings in bronchoalveolar lavage fluid from patients with chronic bronchitis have disclosed an increased recovery of macrophages and neutrophils, ${ }^{27}$ and the first bronchial fraction of the lavage gives the highest neutrophil numbers. ${ }^{10}$ Furthermore, the number of neutrophils in the airways correlated well with airways obstruction $\left(\mathrm{FEV}_{1}\right)$ and increased sputum production. ${ }^{1027}$ Our results revealed high levels of MPO, previously shown to be of local origin, ${ }^{28}$ in bronchial lavage fluid from patients with chronic bronchitis, suggesting that activated neutrophil granulocytes take part in the airways inflammation in these patients. We also found significantly raised levels of IL-8 in the patients, which is in accordance with a recent study reporting high levels of IL-8 in sputum from patients with chronic bronchitis. ${ }^{29}$ IL-8 is a cytokine with chemotactic effects on neutrophil granulocytes ${ }^{29}$ produced by alveolar macrophages and respiratory epithelium. ${ }^{30}$ The high correlation found between the levels of MPO and IL-8 in the present study supports the hypothesis that a specific attraction and activation of neutrophils is present in the airways inflammatory process in patients with chronic bronchitis.

Our results support those of Linden et al who reported increased levels of both ECP and MPO in bronchoalveolar lavage fluid from patients with chronic bronchitis and COPD. ${ }^{31}$ The high levels of ECP found in the present study, together with the strong correlations between ECP and MPO, and ECP and IL-8 respectively, support in vitro data that IL-8 not only attracts and activates neutrophils, but also eosinophil granulocytes. ${ }^{32}$ Thus, airways inflammation in chronic bronchitis is characterised by a broad activation of mucosal granulocytes including eosinophils.
Free hyaluronan, a marker for activated fibroblasts, was significantly raised in the patients with chronic bronchitis in our study. It was not correlated with airways obstruction, as seen in asthmatic patients, ${ }^{33}$ but it was the only mediator to be raised, although not significantly, in patients with a history of recurrent infective exacerbations as opposed to those without.

No specific marker correlated with the development of airways obstruction and COPD. No significant differences were found between the patients with non-obstructive chronic bronchitis and patients with COPD, and no convincing correlations were seen between the levels of markers and $\mathrm{FEV}_{1}$ values.

Interleukin 6 (IL-6) is a multifunctional cytokine produced by most nucleated cells. It has been found in the urine of patients with asymptomatic bacteriuria ${ }^{12}$ and in patients deliberately colonised with Escherichia coli. ${ }^{34} \mathrm{We}$ could, however, find no difference in the levels of IL- 6 between the subjects in this study, although several patients had an intrabronchial bacterial colonisation. ${ }^{18}$ A possible explanation is the diurnal variation as well as peaking kinetics of IL-6 with intermittent production during long term bacterial colonisation. ${ }^{12}$ In our study a single sample was taken from each individual at approximately the same time of day (between 08.30 and 10.00 hours). It is therefore possible that differences in IL- 6 secretion could be shown in a longitudinal study.

Two of the three patients with intrabronchial cultures of Streptococcus pneumoniae had the highest individual levels of MPO, IL-8, and ECP of all subjects studied (table 3 ). The levels of markers in the patients with cultures of Haemophilus influenzae or $\alpha$-haemolytic streptococci did not differ from the patients with negative bacterial cultures. This suggests that intrabronchial colonisation of $S$ pneumoniae through neutrophil activation may exert a more harmful effect on the mucosa than other bacterial strains commonly found in chronic bronchitis.

To obtain samples which predominantly reflect the status of the bronchial epithelium, small volume lavage $(<20 \mathrm{ml})$ in the large airways is of more value than the traditional large lavage. ${ }^{13-15}$ We used a single instillation of $5 \mathrm{ml}$ to minimise the risk of alveolar "contamination". In agreement with Bousquet et $a l^{33}$ we chose to present our data as the concentration of lavaged fluid because (a) the instilled volume was always the same, and (b) no gold standard to compensate for the dilution of the lavaged fluid is valid..$^{356}$ When we used albumin as the denominator for each marker the differences found between the groups were still present, but not statistically significant. However, previous studies found the use of urea or albumin as denominators of protein ratios for the local concentration of markers in lavaged fluid to be inappropriate. ${ }^{3738}$ The similar levels of tryptase, IL-6, and albumin in the subject groups studied also suggest that our data reflect differences in other markers that are not artefactual.

There are some additional methodological 
issues in our study that need to be addressed. Firstly, even if subjects with asthma were excluded, subject atopy was not registered. The similar levels of tryptase in the groups suggest that no large differences in mast cell activation was present, but it is possible that there was some overlap of inflammatory markers in the groups, especially for ECP, which could be due to underlying atopic status in some individuals. In addition, smoking could be a confounding factor in our study since a healthy smoking control group was not included.

Secondly, the assessment of airways inflammation with levels of soluble inflammatory markers in lavage fluid can only be regarded as an indirect evaluation. Our findings have to be substantiated by mucosal bronchial biopsies, and a direct assessment of inflammatory cell activity by immunohistochemical methods.

Thirdly, as cells were not immediately separated from bronchial lavage fluid, it cannot be excluded that intracellular products could have influenced the levels of soluble markers. However, it is unlikely that the differences found between the groups could have been seriously affected since all samples were treated equally, sampled at the same time, and under identical conditions. In addition, our measured differences in ECP and MPO levels are supported by the results reported by Linden et al. ${ }^{31}$

In conclusion, mucosal inflammation in chronic bronchitis is characterised by both activated neutrophils as assessed by high levels of MPO, and activated eosinophils as assessed by high levels of ECP. The activation of these granulocytes may be related to the levels of IL-8. Mast cell activation, typical of atopic asthma, could not be demonstrated. Intrabronchial colonisation of $S$ pneumoniae was related to high levels of MPO, IL-8, and ECP.

The writers are grateful for the generous support from the Swedish Heart and Lung Foundation, the Swedish Society for Medicine, and the Medical Society of Göteborg who made this study possible.

1 Fletcher CM, Pride NB. Definitions on emphysema, chronic bronchitis, asthma, and airflow obstruction: 25 years on from the CIBA symposium. Thorax 1984;39:81-5.

2 Wright JL, Lawson LM, Paré PD, Wiggs BJ, Kennedy S, Hogg JC. Morphology of peripheral airways in current
smokers and ex-smokers. Am Rev Respir Dis 1983;127: smoker

3 Thurlbeck WM. Pathology of chronic airflow obstruction. Chest 1990;97(Suppl):S6-10.

4 Mullen BJ, Wright JL, Wiggs BR, Paré PD, Hogg JC Reassessment of inflammation of airways in chronic bronchitis. BMF 1985;291:1235-9.

5 Saetta M, Stefano Ad, Maestrelli P, Ferraresso A, Drigo R, Potena A, et al. Activated T-lymphocytes and macrophages in bronchial mucosa of subjects with chronic bronchitis. Am Rev Respir Dis 1993;147:301-6.

Am Rev Respir Dis 1993;147:301-6.
6 Djukanovic R, Lai CKW, Wilson JW, Britten JW, Wilson SJ, Roche WR, et al. Bronchial mucosal manifestations of atopy: a comparison of markers of inflammation between atopic asthmatics, atopic nonasthmatics and healthy controls. Eur Respir $\mathcal{F}$ 1992;5:538-44.

7 Ollerenshaw SL, Woolcock AJ. Characteristics of the in flammation in biopsies from large airways of subjects with asthma and subjects with chronic airflow limitation. $A m$ Rev Respir Dis 1992;145:922-7.

8 Laitinen LA, Laitinen A, Haahtela T. Airway mucosal inflammation even in patients with newly diagnosed asthma. Am Rev Respir Dis 1993;147:697-704.

9 Holgate S. Mediator and cytokine mechanisms in asthma. Thorax 1993;48:103-9.

10 Thompson AB, Daughton DM, Robbins R, Ghafouri MA, Oehlerking $M$, Rennard SI. Intraluminal airway in flammation in chronic bronchitis. Am Rev Respir Dis 1989 140:1527-37.
11 Spurzem JR, Thompson AB, Daughton DM, Mueller M, Linder J, Rennard SI. Chronic inflammation is associated with an increased proportion of goblet cells recovered by alveolar lavage. Chest 1991;100:389-93.

12 Hedges S, Stenqvist K, Lidin-Janson G, Martinell J, Sandberg T, Svanborg C. Comparison of urine and serum concentrations of interleukin- 6 in women with acute pyelonephritis or asymptomatic bacteriuria. F Infect Dis 1992; 166:653-6.

13 Yasouka S, Nakayama T, Kawano T, Ogushi F, Doi H, Hayashi $\mathrm{H}$, et al. Comparison of cell profiles of bronchial and bronchoalveolar lavage fluids between normal subjects and patients with idiopathic pulmonary fibrosis. Tohoku $\mathcal{f}$ Exp Med 1985;146:33-45.

14 Lam S, Leriche JC, Kijek K, Phillips D. Effect of bronchial lavage volume on cellular and protein recovery. Chest $1985 ; 88: 856-9$.

15 Rennard SI, Ghafouri MO, Thompson AB, Linder J, Vaughan $\mathrm{W}$, Jones $\mathrm{K}$, et al. Fractional processing of sequential bronchoalveolar lavage to separate bronchial and quential bronchoalveolar lavage to separate bronchial and

16 Boman G, Bäcker U, Larsson S, Melander B, Wåhlander L. Oral acetylcysteine reduces exacerbation rate in chronic bronchitis: Report of a trial organized by the Swedish Society for Pulmonary Disease. Eur f Respir Dis 1983;64: 405-15.

17 Wimberley N, Faling LJ, Bartlett JG. A fiberoptic bronchoscopy technique to obtain uncontaminated lower airway secretions for bacterial culture. Am Rev Respir Dis way secretions for

18 Riise GC, Larsson S, Larsson P, Jeansson S, Andersson BA. The intrabronchial microbial flora in chronic bronchitis patients. A target for $\mathrm{N}$-acetylcysteine therapy? Eur Respir f 1994;7:94-101.

19 Bousquet J, Chanez P, Lacoste JY, Barneon G, Ghavanian $\mathrm{N}$, Enander I, et al. Eosinophilic inflammation in asthma. N Engl f Med 1990;323:1033-9.

20 Peterson CGB, Jömvall $\mathrm{H}$, Venge P. Purification and characterization of eosinophial cationic protein from normal human eosinophils. Eur $¥$ Haematol 1988;40:415-23.

21 Venge P, Strömberg A, Braconier JH, Roxin LE, Olsson I. Neutrophil and eosinophil granulocytes in bacterial infection. Sequential studies of cellular and serum levels of granule proteins. Br $\mathcal{f}$ Haematol 1978;38:475-83.

22 Enander I, Matsson P, Nystrand J, Andersson A-S, Eklund $\mathrm{E}, \mathrm{Bradford} \mathrm{TR}$, et al. A new radioimmunoassay for human mast cell tryptase using monoclonal antibodies. F Immunol Methods 1991;138:39-46.

23 Brandt R, Hedlöf E, Asman I, Bucht A, Tengblad A. A convenient radiometric assay for hyaluronan. Acta Otolaryngol 1978;442:31-5.

24 Helle M, Brakenhoff JP, DeGroot ER, Aarden LA. Interleukin-6 is involved in interleukin-1 induced activities. Eur F Immunol 1988;18:957-9.

25 Lindley I, Aschaver H, Seifert JM, Lam C, Brunowsky W, Kownatski E, et al. Synthesis and expression in Escherichia coli of the gene encoding monocyte-derived neutrophilactivating factor: biological equivalence between natura and recombinant neutrophil-activating factor. Proc Nat Acad Sci USA 1988;85:9199-203.

26 Wenzel SE, Fowler AA, Schwartz LB. Activation of pulmonary mast cells by bronchoalveolar allergen challenge. Am Rev Respir Dis 1988;137:1002-8.

27 Martin TR, Raghu G, Maunder R, Springmeyer SC. The effects of chronic bronchitis and chronic air-flow obstruction on lung cell populations recovered by bronchoalveolar lavage. Am Rev Respir Dis 1985;132:254-60.

28 Schmekal B, Karlsson SE, Linden M, Sundström C, Tegner $\mathrm{H}$, Venge P. Myeloperoxidase in human lung lavage. In flammation 1990;14:447-54.

29 Richman-Eisenstat JBY, Jorens PG, Hebert CA, Ueki I, Nadel JA. Interleukin-8: an important chemoattractant in sputum of patients with chronic inflammatory airway diseases. Am $\mathcal{F}$ Physiol 1993;264:L413-8.

30 Baggiolini M, Walz A, Kunkel SL. Neutrophil-activating peptide-1/interleukin-8, a novel cytokine that activates neutrophils. $\mathcal{F}$ Clin Invest 1989;84:1045-9.

31 Linden M, Rasmussen JB, Piitulainen E, Tunek A, Larson $M$, Tegner $\mathrm{H}$, et al. Airway inflammation in smokers with nonobstructive and obstructive chronic bronchitis. $A m$ Rev Respir Dis 1993;148:1226-32.

32 Shute J. Interleukin-8 is a potent eosinophil chemoattractant. Clin Exp Allergy 1994;24:203-6.

33 Bousquet J, Chanez P, Lacoste JY, Enander I, Venge P Peterson $\mathrm{C}$, et al. Indirect evidence of bronchial inflammation assessed by titration of inflammatory me-
diators in BAL fluid of patients with asthma. $f$ Allergy diators in BAL fluid of patien
Clin Immunol 1991;88:649-60.

34 Hedges S, Anderson P, Lidin-Janson G, de Man P, Svanborg C. IL-6 response to deliberate Gram-negative colonization of the human urinary tract. Infect Immun 1991;59:421-7.

35 Reynolds HY. Bronchoalveolar lavage - state of the art. Am Rev Respir Dis 1987;135:250-63.

36 Thompson AB, Rennard SI. Assessment of airways in flammation in chronic bronchitis. Eur Respir $\mathcal{F} 1993 ; 6$ : 461-4.

37 Klech H, Hutter C. Clinical guidelines and indications for bronchoalveolar lavage (BAL). Eur Respir f 1990;3: 937-74.

38 Schmekel B, Venge P. The distribution of myeloperoxidase eosinophil cationic protein, albumin and urea in sequentia bronchoalveolar lavage. Eur Respir $\mathcal{F} 1991 ; 4: 517-23$. 